This is a postprint version of the following published document:

Martinez-Cisneros C.S., Levenfeld, B. Varez, A.

(2016).Evaluation of polyolefin-based macroporous

separators for high temperature Li-ion batteries.

Electrochimica Acta, 216, pp. 68-78.

DOI: $\underline{10.1016 / \text { j.electacta.2016.08.105 }}$

(C) Elsevier 2016

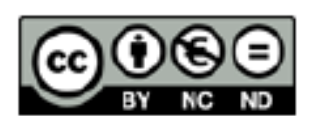

This work is licensed under a Creative Commons Attribution-NonCommercialNoDerivatives 4.0 International License. 


\title{
Evaluation of polyolefin-based macroporous separators for high temperature Li-ionbatteries
}

\author{
C. Martinez-Cisneros ${ }^{\mathrm{a}, * *}$, C. Antonelli ${ }^{\mathrm{a}}$, B. Levenfeld ${ }^{\mathrm{a}}$, A. Varez ${ }^{\mathrm{a}}$, J-Y. Sanchez ${ }^{\mathrm{a}, \mathrm{b}, \mathrm{c}, *}$ \\ a Materials Science and Engineering Department, University Carlos III of Madrid, Spain \\ ${ }^{\mathrm{b}}$ University Grenoble Alpes, LEPMI, 38000 Grenoble, France \\ ${ }^{\mathrm{C}}$ CNRS, LEPMI, 38000 Grenoble, France
}

Keywords:

polymer separator macroporous membrane Li-ion battery high temperature battery

\begin{abstract}
A B S T R A C T
Macroporous separators are critical components in liquid electrolyte batteries. Besides preventing physical contact between electrodes, they enable free ionic transport, electronic isolation and thermal shutdown. Nevertheless, separators also increase electrical resistance and takes up limited space inside the battery, affecting ionic conductivity. Widely used in lithium-ion batteries, commercial polyolefinbased separators operate in a limited temperature range, mainly ranging from $-20^{\circ} \mathrm{C}$ to $+60^{\circ} \mathrm{C}$. The purpose of this contribution is to assess the possibility to use these separators in lithium-ion batteries operating at extended temperatures, i.e. between $-20^{\circ} \mathrm{C}$ and $120^{\circ} \mathrm{C}$. For this purpose, four commercially available macroporous separators based on polyethylene and polypropylene, were investigated. To determine the effect of temperature on their performance, they were aged for one week at $120^{\circ} \mathrm{C}$. Evolution of their morphology and thermomechanical behavior was investigated using XRD, SEM, DSC, TGA and DMA. The thermal aging impact on the ionic conductivity was also investigated using $\mathrm{LP} 3 \mathrm{O}^{\mathbb{R}}$ as reference electrolyte. Thermal aging, i.e. partial clogging of the porosity, was found to have significant effects mainly on mechanical strength, morphology and conductivity.
\end{abstract}

\section{Introduction}

In any battery, the electrolyte, an ionic conductor, is one of the main contributors to its internal resistance. As the battery performance - voltage, energy and power density - mainly depends on the negative and positive electrodes (active materials, formulation, etc.), the main function of the electrolyte relies on ensuring ionic conductivity without compromising such performance by creating thick and resistive interfaces or by producing chemical/electrochemical degradation (by-products reacting eventually with active materials). To minimize the electrolyte contribution to the battery internal resistance, its ionic conductivity must be as high as possible while its thickness should remain as low as possible. Nevertheless, such slimming could be detrimental to mechanical properties, increasing the risks of short circuits by direct contact between the electrodes. To avoid such

\footnotetext{
* Corresponding author at: Materials Science and Engineering Department, University Carlos III of Madrid, Spain.

** Corresponding author.

E-mail addresses: cymartin@ing.uc3m.es (C. Martinez-Cisneros), jeasanch@ing.uc3m.es (J.-Y. Sanchez).
}

inconvenience, both, rechargeable and non-rechargeable batteries include a material endowed with electronic insulation properties, which allows physically separating the electrodes and preventing short circuits. In all solid-state batteries, this separation is provided by ion-conducting glasses or crystalline ceramics. Separation can be also provided by ion-conducting polymers, i.e. polymer electrolytes made of salts dissolved in a solvating polymer matrix. Lithium battery prototypes based on these polymer electrolytes have demonstrated good cyclability at 100\% DOD (Depth of Discharge), very low self-discharge and high safety [1]. Although extensive researches [2-6] have allowed improving room temperature conductivity of these ion-conductive separators, reaching 0.1 $\mathrm{mS} / \mathrm{cm}\left(\right.$ at $32^{\circ} \mathrm{C}$ ) [7], they are still insufficient to address the requirements of batteries dedicated to portable electronics. In most batteries, separation between electrodes is mainly achieved by a polymer material: the so-called separator. This separator must fulfill requirements that are sometimes antagonistic, e.g. providing high mechanical strength and allowing high conductivity. Although the term separator is often restricted to porous polymers, pore-free polymers can be an actual and cost-cutting alternative. Dealing with the latter, they were early proposed by Feuillade et al. [8], who 40 years ago claimed the concept of thin lithium batteries and used a variety of thermoplastic based dense membranes, e.g. 
PAN (polyacrylonitrile) or PVdF-HFP (polyvinylidene-co-hexafluoropropene) copolymers. These membranes were swollen by a liquid electrolyte, leading to what has been called plasticized polymer electrolyte (PPE), gelled polymer electrolyte (GPE) or hybrid polymer electrolyte (HPE). However, since a decrease in melting and glass transition temperatures is commonly observed after swelling the polymer matrix by the liquid electrolyte, the first denomination is usually preferred. Indeed, gel formation (GPE) occurs very rarely and HPE formulation involves, concomitantly, macromolecular and molecular solvents such as POE poly(oxyethylene) swelled by liquid electrolytes [9]. Feuillade et al. [8] early pointed out the instability of PAN versus lithium metal, which was later confirmed by Scrosati et al. [10]. This instability, ascribed to the hydrogen in alpha position of the nitrile [11], can be overcome by substituting the PAN tertiary hydrogen by a methyl, e.g. polymethacrylonitrile (PMAN). Owing to hydrogen bonding, PAN forms a gel in current liquid electrolytes, while PMAN homo- and copolymers dissolve, requiring membrane cross-linking. Despite its instability in reduction, porous PAN membranes were prepared by phase inversion, the authors claiming a high oxidative stability [12]. PVdF homopolymer is a semi- crystalline thermoplastic, whose crystallinity and melting temperature, $T_{m}$, depend on its head-to-tail content. It exhibits, upon its swelling in liquid electrolytes, poor conductivity, which makes it unsuitable for pore-free PPE. On the other hand, the copolymerization of VdF with HFP (unable to homopolymerize) results in copolymers VdF-HFP, whose crystallinity and $\mathrm{T}_{\mathrm{m}}$ decrease with the HFP content, while $\mathrm{T}_{\mathrm{g}}$ increases. Hence, VdF-HFP copolymers have been extensively used as PPE, in particular in the Post Li-Ion (PLION) battery developed by Bellcore [13]. The great discrepancy in the reported conductivity for poly(VdF-HFP)-based PPE could be ascribed to (i) the polymer grade, i.e. the HFP content, and (ii) the porosity arising from the film casting process $[14,15]$. Porous separators are indisputably the most widely used separators. Due to the average pore diameter, they have often been named microporous separators. Nevertheless, according to IUPAC nomenclature, "macroporous separators" is more appropriate. Indeed, IUPAC nomenclature ranks the pores according to their width ( $\mathrm{w}$ ) as micropores - $\mathrm{w}<2 \mathrm{~nm}-$ mesopores - $2<\mathrm{w}<50$ - and macropores $\mathrm{w}>50 \mathrm{~nm}$. Although essential for a proper battery performance and safety, separators have not given rise to extensive academic researches [16]. In particular, due to the highly difficult dissolution of polyethylene and polypropylene, academic research has not focused on the elaboration of separators based on them. On the other hand, several polymers that can be actually dissolved have been tested, mainly PVdF $[17,18]$ or high performance polymers such as polyimides [19]. Indeed, when PVdF is not able to full fit requirements for being used as PPE, some advantage could be taken from its crystallinity and melting temperature to shaping it into macroporous separators [20,21]. The McMullins Number, $\mathrm{N}_{\mathrm{M}}$, of macroporous PVdF, around 3.6, enables to obtain an improved performance of Li-ion batteries dedicated to GSM applications [22]. Moreover, its affinity for cyclic and acyclic carbonates [14,17] enhances pore-through wettability regarding usual Li-ion liquid electrolytes, which (i) limits conductivity losses and (ii) retains the liquid electrolyte into the porous structure. Nevertheless, such affinity has also a detrimental impact on mechanical strength, decreasing melting temperature, crystallinity content and glass transition temperature of the porous PVdF $[14,17]$. Recently, the use of PVdF/NCC nanocomposites based on NanoCrystallineCellulose led to a $300 \%$ increase in storage modulus and allowed the PVdF/NCC to be shaped into $\sim 20 \mu \mathrm{m}$ thick macroporous separators. Using this approach, the specific energy of a $\mathrm{LiC}_{6} / \mathrm{LiNMO}$ battery was increased by roughly $30 \%$ with regard to the same battery equipped with a $24 \mu \mathrm{m}$ thick Celgard $\AA 2400$ separator [23]. Nowadays, the use of commercial polyolefin-based macroporous separators has been widespread. Their assets lie on (i) excellent chemical stability, (ii) wide electrochemical stability window and (iii) high mechanical strength. Furthermore, the possibility of shutting-down resulting e.g. from polyethylene,

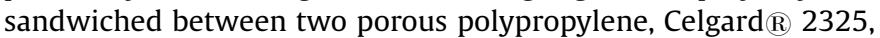
which, upon melting, clogs the polypropylene porosity, is a safety guarantee. The solubility parameters of these hydrophobic polyolefins, very far from those of the used polar aprotic solvents, favor neither the pore wetting by the liquid electrolytes nor their retention. Their introduction in a liquid electrolyte results therefore in a substantial decrease of the ionic conductivity, MacMullins Number $\left(\mathrm{N}_{\mathrm{M}}\right)$ ranging between 5 and 20 [24]. The main objective of this contribution is to investigate battery polymer separators able to operate in a wide temperature range, i.e. between -20 to $+120^{\circ} \mathrm{C}$. Indeed, they could be successfully applied to direct conversion-storage of photovoltaic energy (rooftop power stations), hybridizing specifically designed batteries and solar panels. Such batteries, in particular in Middle Est countries, would operate in an extended temperature range, as compared to current batteries, dedicated to portable electronics and even to electric vehicles. Due to the unusually wide operating temperature range and the long lifetime required for such batteries, binder-free solid electrodes [25], in which the negative is lithium titanate, LTO, would be preferable. Regarding electrolytes, 1) inorganic solid electrolytes should be discarded as allsolid-state batteries are currently unadapted to large surface areas, 2) solvent-free polymer electrolytes are usually disqualified because of their very low conductivity at sub-ambient temperatures and 3) due to their affinity with most of the liquid electrolytes, which results in a huge swelling even their dissolution at high temperature, PVdF based dense and porous separators should also be discarded. Therefore, in this work we have performed a comparative study of commercial polyolefin-based macroporous separators with special attention paid on their exsitu thermal aging. Thermal, thermomechanical and structural comparisons between pristine and aged materials were performed on the selected separators. Even though $\mathrm{LP}^{\mathrm{B}} \mathrm{O}^{\mathrm{R}}$ electrolyte, owing to its poor thermal stability, cannot be used for this application, it was applied in this study to assess the impact of the thermal aging on conductivity of the sets electrolyte + separator. The impact of

Table 1

Main properties of separators under study according to their datasheets.

\begin{tabular}{|c|c|c|c|c|}
\hline & \multicolumn{2}{|l|}{ Celgard $^{(\mathbb{R})}$} & \multicolumn{2}{|l|}{ Solupor ${ }^{\mathbb{R}}$} \\
\hline & 2400 & 2325 & 10P05A & 7P03A \\
\hline Composition & Polypropylene (PP) & $\mathrm{PP} / \mathrm{PE} / \mathrm{PP}$ & Polyethylene(PE) & PE \\
\hline Thickness ( $\mu \mathrm{m})$ & 25 & 25 & 60 & 50 \\
\hline Porosity (\%) & 41 & 39 & 83 & 85 \\
\hline Pore Size $(\mu \mathrm{m})$ & 0.043 & 0.028 & 0.500 & 0.300 \\
\hline Tensile Strength, MD & $1420\left(\mathrm{Kg} / \mathrm{cm}^{2}\right)$ & $1700\left(\mathrm{Kg} / \mathrm{cm}^{2}\right)$ & $20 \mathrm{MPa}$ & $15 \mathrm{MPa}$ \\
\hline Tensile Strength, TD & $140\left(\mathrm{Kg} / \mathrm{cm}^{2}\right)$ & $150\left(\mathrm{Kg} / \mathrm{cm}^{2}\right)$ & - & - \\
\hline
\end{tabular}

MD: machine direction; TD: transverse direction. 
the separators' thermal aging was evaluated through structural, thermal, mechanical and electrical characterizations.

\section{Experimental}

\subsection{Material}

Four commercial macroporous polyeolefin separators from two different suppliers were used for this study: Celgard ${ }^{\mathbb{R}} 2400$, Celgard ${ }^{\mathbb{R}} 2325$, Solupor ${ }^{\circledR} 10 \mathrm{P05A}$ and Solupor ${ }^{\circledR} 7 \mathrm{P03A}$. The Celgard $^{\circledR}$ separators are typically prepared by a dry process, which includes extrusion and annealing followed by stretching. Hence, pores in this kind of membranes are strongly machinedirection oriented, producing an anisotropic behavior. On the other hand, Solupor ${ }^{\circledR}$ separators are usually prepared using a wet process, where a mixture of polymer-paraffin oil-additives is extruded in gel form, followed by extracting the paraffin oil and additives using a volatile solvent to form a microporous structure. The resulting pores, in this case, are non-oriented and, therefore, an isotropic behavior is expected. Table 1 presents the most relevant properties regarding the investigated separators according to datasheets provided by suppliers.

\subsection{Scanning electron microscopy (SEM)}

The structural/morphological characterization of the films was performed using a Philips XL-30 scanning electron microscope (SEM) operating at $5-10 \mathrm{kV}$, in accordance to the material resistance. For avoiding surface charge effects, before imaging, samples were gold coated using the sputter coater Polaron SC7610 (Fision Instruments, UK) at $18 \mathrm{~mA}$ under $1 \times 10^{-2}$ mbar vacuum for 2 minutes.

\section{3. $X$-Ray diffraction (XRD)}

XRD measurements were carried out to estimate the change of crystallinity within separators before and after thermal aging using a Philips X'PERT MPD diffractometer ( $\mathrm{Cu} \mathrm{K} \alpha$ radiation) operating at $40 \mathrm{kV}$ and $40 \mathrm{~mA}$. The XRD patterns were recorded over a $2 \theta$ range of $5-80^{\circ}$ using a step scan of $0.02^{\circ}$ and a counting time of 1 second per step. Samples were placed on a zero background Silicon holder.

\subsection{Porosity measurements}

Porosity was characterized by mercury intrusion porosimetry using a Micrometrics AutoPore IV 9510. Measurements were carried out over a pressure range from $0.7 \times 10^{-4} \mathrm{~Pa}$ to $414 \times 10^{5} \mathrm{~Pa}$, considering a surface tension of $484 \times 10^{-5} \mathrm{~N} \mathrm{~cm}^{-1}$ and a contact angle of $141^{\circ}$, for all samples.

\subsection{Contact angle}

To study wettability, the physical contact angle of separators was measured at room temperature using deionized water (as reference liquid) and $\mathrm{LP}_{30}{ }^{\circledR}\left(1 \mathrm{M} \mathrm{LiPF}_{6}\right.$ in a $1 / 1(\mathrm{w} / \mathrm{w})$ mixture of ethylene carbonate and dimethyl carbonate). Measurements were
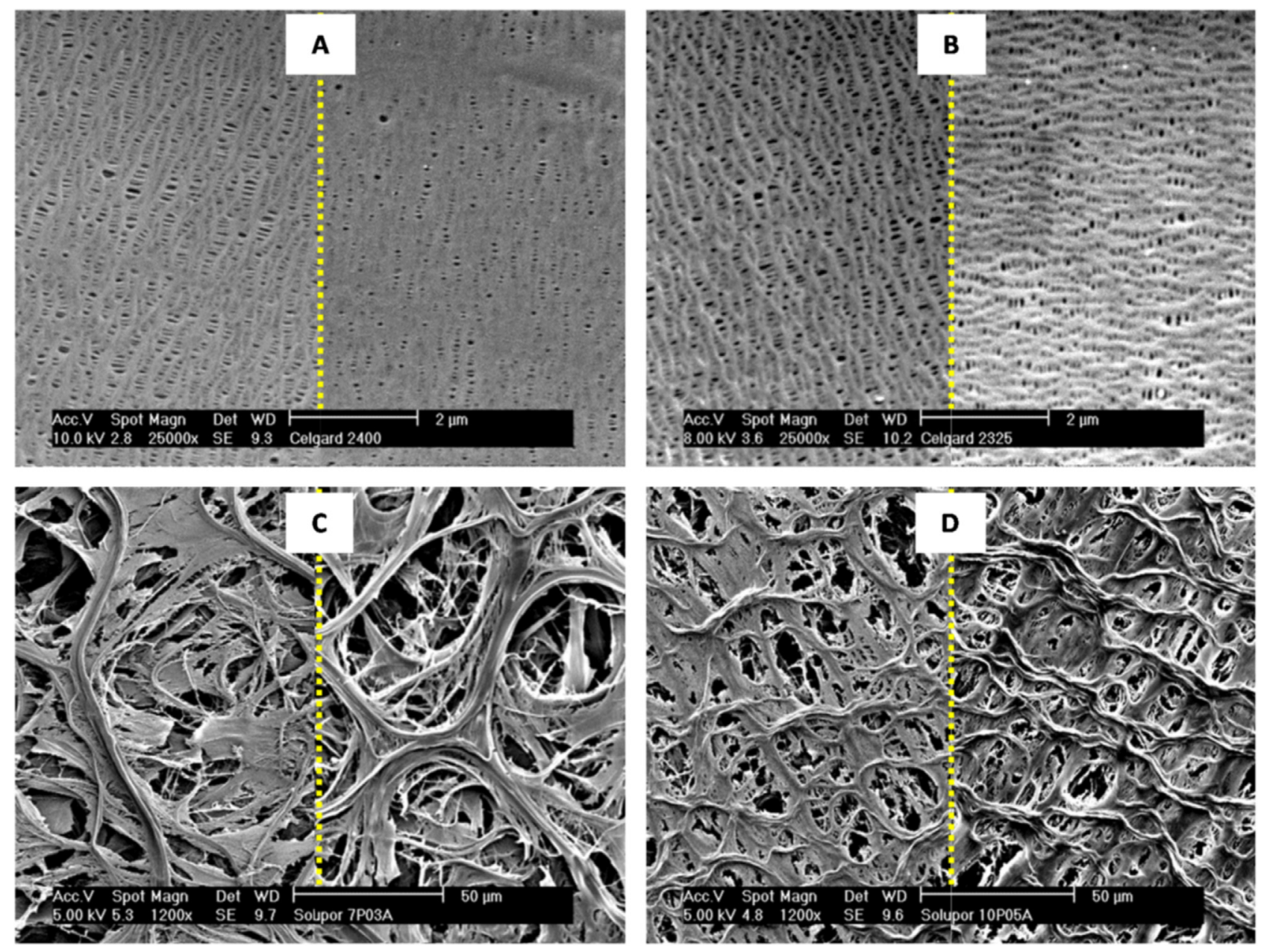

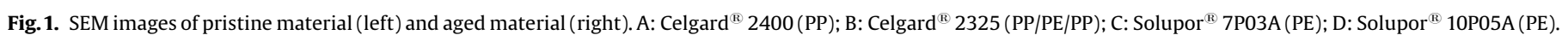


carried out using an OCA 15plus contact angle system (Neurtek Instruments, Spain).

\subsection{Thermal and thermomechanical characterization}

The thermogravimetric analysis (TGA) of all separators was performed using a Pyris ${ }^{1}$ TGA (PerkinElmer, USA) thermogravimetric analyzer. Samples were heated in a platinum crucible from $30^{\circ} \mathrm{C}$ to $700^{\circ} \mathrm{C}$ at a heating rate of $10^{\circ} \mathrm{C} / \mathrm{min}$ under air atmosphere. Onset temperature $\left(\mathrm{T}_{\text {onset }}\right.$ ) was determined as the point of intersection between the tangent drawn at the point of greatest slope and the extrapolated base line. In case of polypropylene based separators, additional experiments were performed in inert gas atmosphere to ascribe undoubtedly their thermal decomposition at their ceiling temperature.

Differential scanning calorimetry (DSC) studies were carried out to determine melting temperature before and after annealing. For this purpose, samples $\sim 7.5 \mathrm{mg}$ were heated up from $30^{\circ} \mathrm{C}$ to $200^{\circ} \mathrm{C}\left(20^{\circ} \mathrm{C} / \mathrm{min}\right)$ in closed aluminum capsules using a DSC822e (Mettler Toledo, Switzerland) under a $50 \mathrm{~mL} / \mathrm{min}$ constant $\mathrm{N}_{2}$ (g) flow.

Thermomechanical characterization was conducted on samples $3.5 \times 4 \mathrm{~mm}^{2}$ using a DMA Q800 (TA Instruments, USA). Tensile strength was investigated at constant temperature $\left(30^{\circ} \mathrm{C}\right)$ by ramping force from $0.1 \mathrm{~N} / \mathrm{min}$ to $15 \mathrm{~N} / \mathrm{min}$ at $1 \mathrm{~Hz}$, oscillation amplitude of $15 \mu \mathrm{m}$. Measurements were carried out by quintuplicate. To determine storage moduli (E'), samples were also evaluated under a temperature ramp ranging from $30^{\circ} \mathrm{C}$ to $200^{\circ} \mathrm{C}$, heating rate of $5^{\circ} \mathrm{C} / \mathrm{min}$, at a constant strain (15 $\mu \mathrm{m}$ amplitude) and frequency $(1 \mathrm{~Hz})$.

\subsection{Ionic conductivity measurements}

Conductivity measurements were performed in an Impedance/ Gain-Phase Analyzer SI1260 (Solartron, UK) using LP30 ${ }^{\circledR}$ as electrolyte. Impedance tests were carried out by applying a $100 \mathrm{mV}$ amplitude signal in the $1 \mathrm{~Hz}-10 \mathrm{MHz}$ frequency range. Measurements at different temperatures while cooling from $30^{\circ} \mathrm{C}$ to $-30^{\circ} \mathrm{C}$ were carried out using stainless steel blocking electrodes $(\Phi=12 \mathrm{~mm}$ ) embedded in a Swagelok-Teflon cell. The assembly of cells was performed in argon atmosphere to prevent moisture absorption. Previous to assembly, electrodes were dried overnight at $80^{\circ} \mathrm{C}$ under vacuum and separators were immersed in LP30 ${ }^{\mathrm{R}}$ during controlled periods of time under argon atmosphere. To obtain reproducible measurements, we established a dwell time of 15 minutes before taking every measurement, this time was enough for the system to reach a stable temperature.

\section{Results and discussion}

Current commercially available batteries based on polyolefin separators operate in a very limited temperature range, mainly ranging from $-20^{\circ} \mathrm{C}$ to $+60^{\circ} \mathrm{C}$. However, rooftop power stations, vide supra, require a much wider operation temperature. To determine the effect of temperature on their performance, separators presented in Table 1 were exposed to a thermal aging
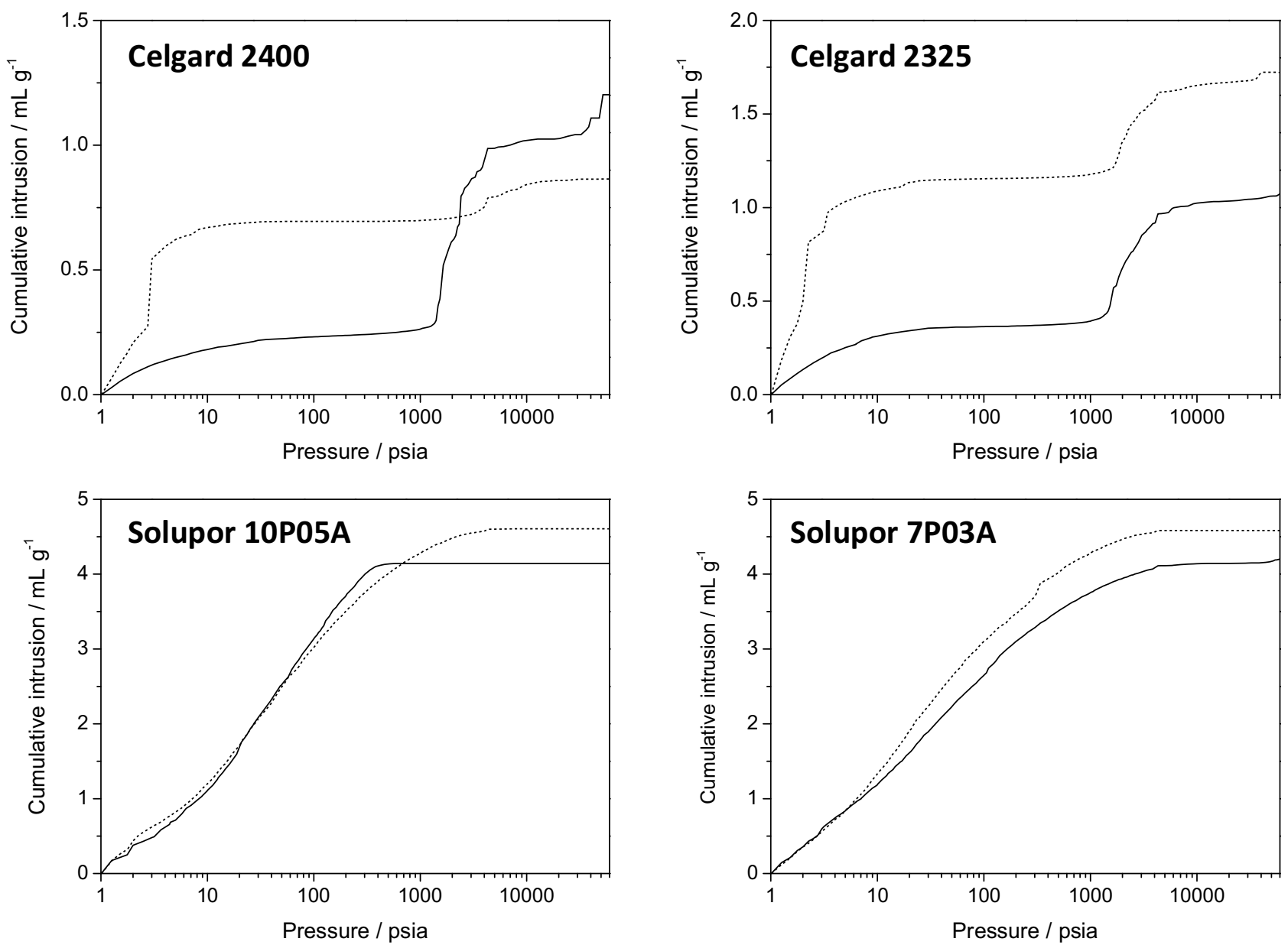

Fig. 2. Cumulative intrusion mercury in all separators under study. Continuous line: pristine material; dash line: aged material. 
process at $120^{\circ} \mathrm{C}$ for one week. Evolution of their morphology, thermomechanical behavior and effect on ionic conductivity was investigated using several characterization techniques.

\subsection{Morphology and microstructural characterization}

\subsubsection{Scanning electron microscopy (SEM)}

Fig. 1 shows the surface morphology of the four investigated pristine and thermally aged separators. The anisotropic manufacturing process used in Celgard ${ }^{\circledR}$ separators lead to pores lengthened and oriented in the same direction, as shown in Figs. $1 \mathrm{~A}$ and $1 \mathrm{~B}$. It can also be noticed that every pore is entrapped by two nanofibers from the narrower side. Such structure is usually obtained after stacked lamellae are separated during the stretching process [26]. On the other hand, a fibrous network with larger pores is observed in Solupor ${ }^{\circledR}$ separators, suggesting an isotropic behavior and an improved capability to establish contact between electrodes and electrolyte. After aging samples during one week at $120^{\circ} \mathrm{C}$, Solupor ${ }^{\circledR} 10 \mathrm{P} 05 \mathrm{~A}$ exhibited only negligible morphology changes, while no significant changes were observed in Solupor ${ }^{\circledR} 7 \mathrm{P03A}$, since according to SEM images, morphology remains apparently unaltered. Nevertheless, in case of Celgard ${ }^{\circledR}$ separators, besides a clear reduction in pores length, partial clogging was perceived in both separators, PP (Celgard $\left.{ }^{\circledR} 2400\right)$ and PP/PE/PP (Celgard ${ }^{\circledR} 2325$ ). This is a significant handicap regarding the use of these separators at high temperature, since besides shrinkage might cause electrical shortcut, conductivity is expected to be significantly decreased.

\subsubsection{Porosimetry characterization}

As seen in Fig. 2, a significant difference regarding mercury intrusion behavior was found when comparing Solupor ${ }^{\circledR}$ and Celgard $^{\circledR}$ separators. Solupor ${ }^{\circledR}$ separators presented higher maximum cumulative intrusion than Celgard ${ }^{\mathbb{B}}$ ones. This could be ascribed to the wider pore diameter associated to the first ones. Moreover, while Solupor ${ }^{\circledR}$ separators showed a unique gradual increment, in case of Celgard ${ }^{\mathbb{B}}$ separators two clear thresholds were clearly identified, suggesting the presence of two main pore size distributions. This hypothesis was later reinforced by statistics analysis, through which the appearance of two pore diameter distributions were noticed for Celgard ${ }^{\circledR}$ separators.

Regarding the effect of the thermal aging process on the mercury intrusion profile, only slight differences were observed on Solupor $^{\mathbb{R}}$ separators, which are in agreement with the microstructural study performed by SEM images, where only small variations in morphology were observed. Nevertheless, in case of Celgard $^{\mathbb{R}}$ separators, although a similar trend was observed in pristine and aged samples, the first mercury intrusion occurred at lower pressure in aged samples when compared to pristine ones. This could be ascribed to the reduction of the quantity of small pores (probably collapsed during the aging process), which led to an increase in the average pore diameter. Moreover, in agreement with the SEM study, pores were, in general, more rounded, instead

Table 2

Porosity $\varepsilon(\%)$ and apparent density measured by mercury intrusion.

\begin{tabular}{lll}
\hline Separator & $\varepsilon \%$ & Apparent Density $(\mathrm{g} / \mathrm{mL})$ \\
\hline Celgard $^{\mathbb{R}} 2400$ & 45.4 & 0.69 \\
Celgard $^{\mathbb{R}} 2400$ (Aged) & 41.6 & 0.82 \\
Celgard $^{\mathbb{R}} 2325$ & 44.1 & 0.74 \\
Celgard $^{\mathbb{R}} 2325$ (Aged) & 57.4 & 0.78 \\
Solupor $^{\mathbb{R}} 10 \mathrm{P05A}$ & 75.9 & 0.68 \\
Solupor $^{\mathbb{R}}$ 10P05A (Aged) & 66.9 & 0.49 \\
Solupor $^{\mathbb{R}}$ 7P03A & 78.6 & 0.88 \\
Solupor $^{\mathbb{R}}$ 7P03A (Aged) & 69.2 & 0.49 \\
\hline
\end{tabular}

of lengthened. Hence, it could be suggested that such increase in symmetry enhances liquid penetration. Table 2 summarizes results obtained through mercury intrusion regarding porosity (\%) and apparent density. Porosity percentage values measured by mercury intrusion were in range of values reported at the datasheet provided by the suppliers. Differences could be attributed to variation in experimental conditions during measurements regarding the experimental set-up we used and the supplier's. For Celgard ${ }^{\mathbb{R}} 2400$, Solupor ${ }^{\mathbb{R}} 7 \mathrm{P03A}$ and Solupor ${ }^{\circledR} 10 \mathrm{P} 05 \mathrm{~A}$, a slight reduction in percentage of porosity was noticed at aged samples when compared to pristine ones. However, Celgard ${ }^{\circledR} 2325$ presented a slight increment in percentage of porosity. This could be associated to variations in the average pore size (small pores collapsed during aging).

\subsection{3. $X$-Ray diffraction (XRD)}

Fig. 3 presents the XRD patterns obtained for all samples. Solupor ${ }^{\circledR}$ separators presented sharp and distinct peaks around $2 \theta=21.7^{\circ}$ and $24.1^{\circ}$, which are characteristic of high molecular weight (HMW) semi-crystalline polyethylene (PE) [27]. On the other hand, Celgard ${ }^{\circledR} 2400$ showed sharp peaks at 14.1, 17.0 and 18.6, which are typical of isotactic polypropylene (PP) [28]. Given its trilayered structure (PP/PE/PP), Celgard ${ }^{\circledR} 2325$ presented both sets of peaks corresponding to $\mathrm{PP}$ and $\mathrm{PE}, 14.1,17.0,18.6,21.7$ and 24.0. Annealing, in particular at temperatures close to $\mathrm{T}_{\mathrm{m}}$, generally leads to crystal thickening and an increase in subsequent $\mathrm{T}_{\mathrm{m}}$. Its effect however depends on the annealing time, the annealing temperature, the molecular weight distribution, the molar mass, the solution or the bulk state, etc. Dealing with the separators, their macroporous nature might influence the crystallinity evolution. The main effect associated to the thermal aging process (annealing), was a decrease in the intensity of peaks (dash lines in Fig. 3), which was observed in all cases, suggesting a decrease in crystallinity. Considering the highest diffraction peak for each separator, the highest reduction in intensity was found to occur for Celgard ${ }^{\circledR} 2400$, where a decreased of $73 \%$ was estimated for aged material regarding pristine one. Regarding Celgard ${ }^{\circledR} 2400$ it must

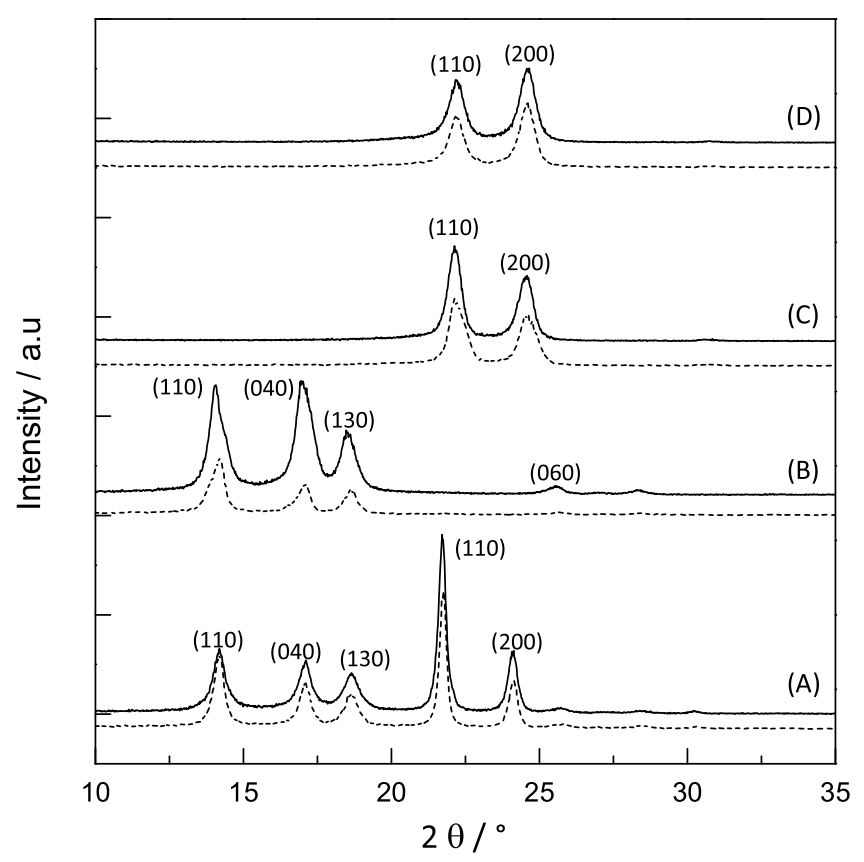

Fig. 3. XRD patterns for all separators: (A) Celgard ${ }^{\mathbb{B}} 2325$; (B) Celgard ${ }^{\mathbb{B}} 2400$; (C) Solupor $^{\mathbb{B}}$ 10P05A; (D) Solupor ${ }^{\mathbb{B}}$ 7P03A. Solid lines: pristine material; dashed lines: aged samples (after annealing at $120^{\circ} \mathrm{C}$ during one week). 
be underlined that the crystallinity, which is favored by the orientation induced by the stretching process, should decrease following one week annealing at $120^{\circ} \mathrm{C}$. If the interpretation is fairly easy in the case of Celgard ${ }^{\mathbb{R}} 2400$, it is far less obvious for the other separators. In general terms, from the experimental data, the trend was $\quad$ Celgard $^{\mathbb{R}} 2400 \quad(73 \%)>$ Solupor $^{\mathbb{R}} 10 \mathrm{P} 05 \mathrm{~A}$ $(30 \%)>$ Celgard $^{\circledR} 2325$ (24\%) $>$ Solupor ${ }^{\circledR} 7$ P03A (11\%). Regarding Bragg diffraction angles, no significant changes were observed.

\subsubsection{Contact angle}

Wettability is a crucial parameter in battery separators, since they should be able to effectively retain the electrolyte. In this sense, several attempts have been reported to improve the wetting of separators by lithium battery aprotic electrolytes [29,30]. Poor wettability could lead to i) incomplete filling of the porosity and ii) uneven distribution of the electrolyte, both producing poor long term stability and lower load capacity. Wettability of separators mainly depends on porosity, surface roughness, viscosity of the electrolyte and chemical affinity between it and the membrane surface. To investigate wettability, contact angle measurements were performed on all samples using deionized water and LP30 ${ }^{\mathbb{R}}$ as reference liquids. It should be surprising to measure contact angles with a protic solvent $\left(\mathrm{H}_{2} \mathrm{O}\right)$ when liquid electrolytes used in Li-ion are polar but aprotic. However, measurements of contact angle with water is a reference of this technique. Moreover, by selecting an LTO negative electrode $\left(\sim+1.5 \mathrm{~V} v s \mathrm{Li} / \mathrm{Li}^{+}\right)$it is possible to use protic polar solvents, e.g. N-methyl-acetamide and even Protic Ionic Liquid (PIL), successfully used by Balducci et al. [31]. Actually, from the water contact angle measured, it can be inferred that the pore wetting of these separators by both protic and acidic PIL should not be favored. Since no significant differences were observed among samples based on the same surface material, Fig. 4 only presents results obtained in accordance to the separator surface (Celgard ${ }^{\mathbb{R}} 2400$ for PP and Solupor ${ }^{\circledR} 10 \mathrm{P} 03 \mathrm{~A}$ for PE) and liquid. As seen there, pristine materials presented, independently of the surface material, an expected highly hydrophobic behavior, with contact angles ranging from $111^{\circ}$ to $124^{\circ}$, being the highest values those observed on PE surfaces (Solupor ${ }^{\circledR}$ ). However, an improved wettability was noticed when using an aprotic polar electrolyte $($ LP30 $®)$, being slightly higher in case of PE surfaces. This might suggest that larger pores favor wettability in case of the reference electrolyte $L P 30^{\circledR}$. Regarding the effect of thermal aging, independently of the surface material and liquid, although no significant differences were observed, slightly lower contact angles were detected on aged samples, suggesting, against predictions, an increased wettability.

\subsection{Thermal and thermomechanical behavior}

\subsubsection{Thermogravimetric analysis (TGA)}

Thermal stability was studied by TGA in air atmosphere (Fig. $5 \mathrm{~A}$ left). The thermal degradation of pristine Celgard ${ }^{\mathbb{R}} 2400$, from roughly $290^{\circ} \mathrm{C}$, could be ascribed to its depolymerization to, at least partly, monomer [32,33], since the ceiling temperature of PP is close to $300^{\circ} \mathrm{C}$, although bond cleavage is not discarded. This thermal degradation of polypropylene based separators does neither affect the Li-ion battery operation nor limit exothermal runaway. On the other hand, in case of dramatic event with fire, this depolymerization releases highly volatile $\left(\mathrm{B}_{\mathrm{p}} \sim-46^{\circ} \mathrm{C}\right)$ and flammable gas $\left(\mathrm{F}_{\mathrm{p}} \sim-108^{\circ} \mathrm{C}\right)$, which from about $300^{\circ} \mathrm{C}$ would feed a starting fire. PE-based separators (Solupor ${ }^{\mathbb{R}}$ ) exhibited two massloss zones. The first one, almost negligible, probable related to the presence of additives in the separator composition [34]. The second weight loss, related to the polymer degradation, was delayed regarding PP, since PE ceiling temperature exceeds $600^{\circ} \mathrm{C}$. Therefore, degradation should be exclusively ascribed to bond cleavages. In case of the trilayered separator (Celgard ${ }^{\circledR} 2325$ ), the onset of its weight loss was delayed with respect to Celgard ${ }^{\mathbb{R}} 2400$. This fact could be attributed to the propene monomer and, possibly, other by-products originating from the PP depolymerization, which might be temporarily trapped by the PE layer, delaying the PP weight loss. Regarding the aging effect, according to Fig. 5B left, thermal stability seems roughly unaffected by one week exposure at $120^{\circ} \mathrm{C}$, since no significant changes were observed. One could be feared that polypropylene (Celgard ${ }^{\mathbb{R}}$ ) aging, performed in air, might undergo oxidation. Indeed, the tertiary C-H energy dissociation of the 'methide' of a stabilizer-free polypropylene is significantly lower than that of the secondary one of polyethylene, $380 \mathrm{~kJ} / \mathrm{mole}$ and $393 \mathrm{~kJ} / \mathrm{mole}$, respectively [35]. This instability leads to hydroperoxide, $\mathrm{P}-\mathrm{O}-\mathrm{O}-\mathrm{H}$, formation in presence of oxygen. Regarding non-stabilized polypropylene, the induction time of oxidation has been reported to be close to $19 \mathrm{H}$ at $100{ }^{\circ} \mathrm{C}$. Indeed, polypropylene processing requires the addition of stabilizers. From the same thermal behavior being observed at TGA, for pristine and aged Celgard ${ }^{\circledR}$, one could conclude that the separator stabilization has been efficient. Therefore, it can be

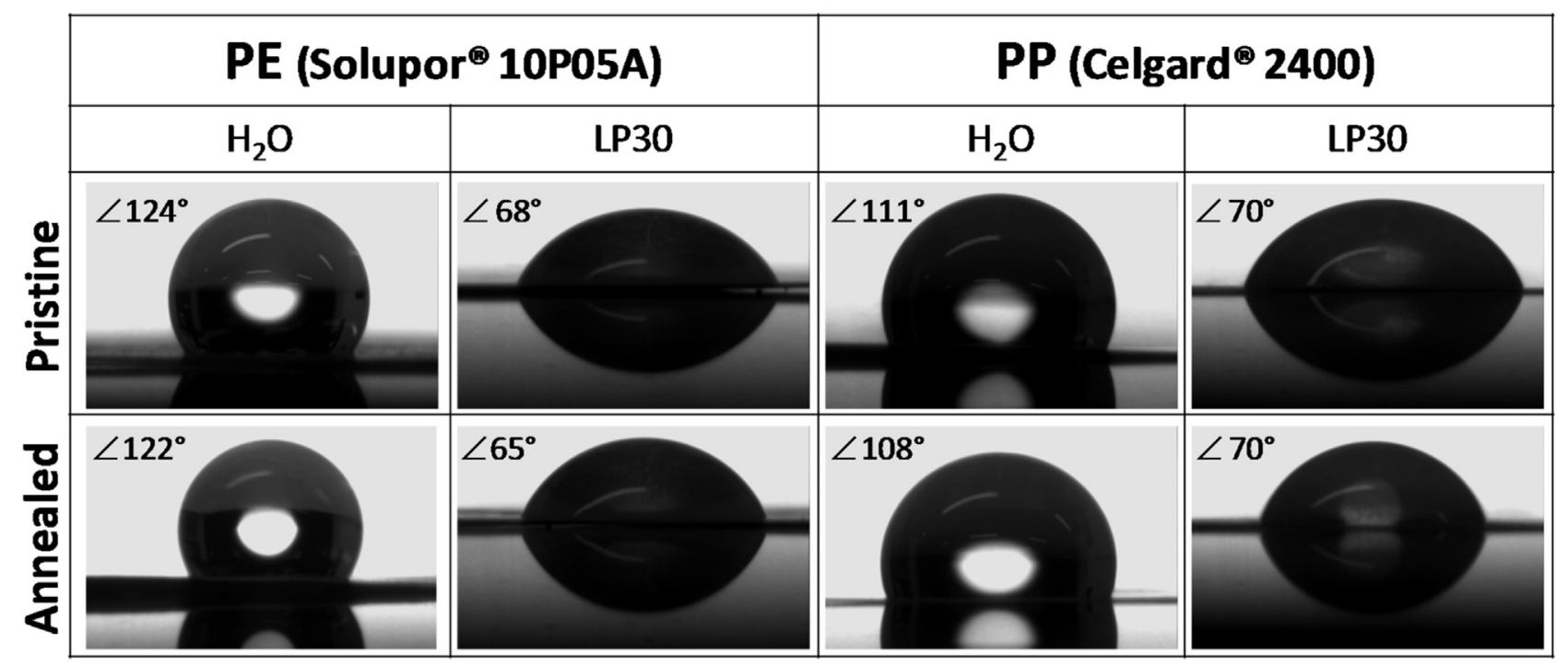

Fig. 4. Contact angle on the separators' surface using deionized water and LP30 as reference liquids. 

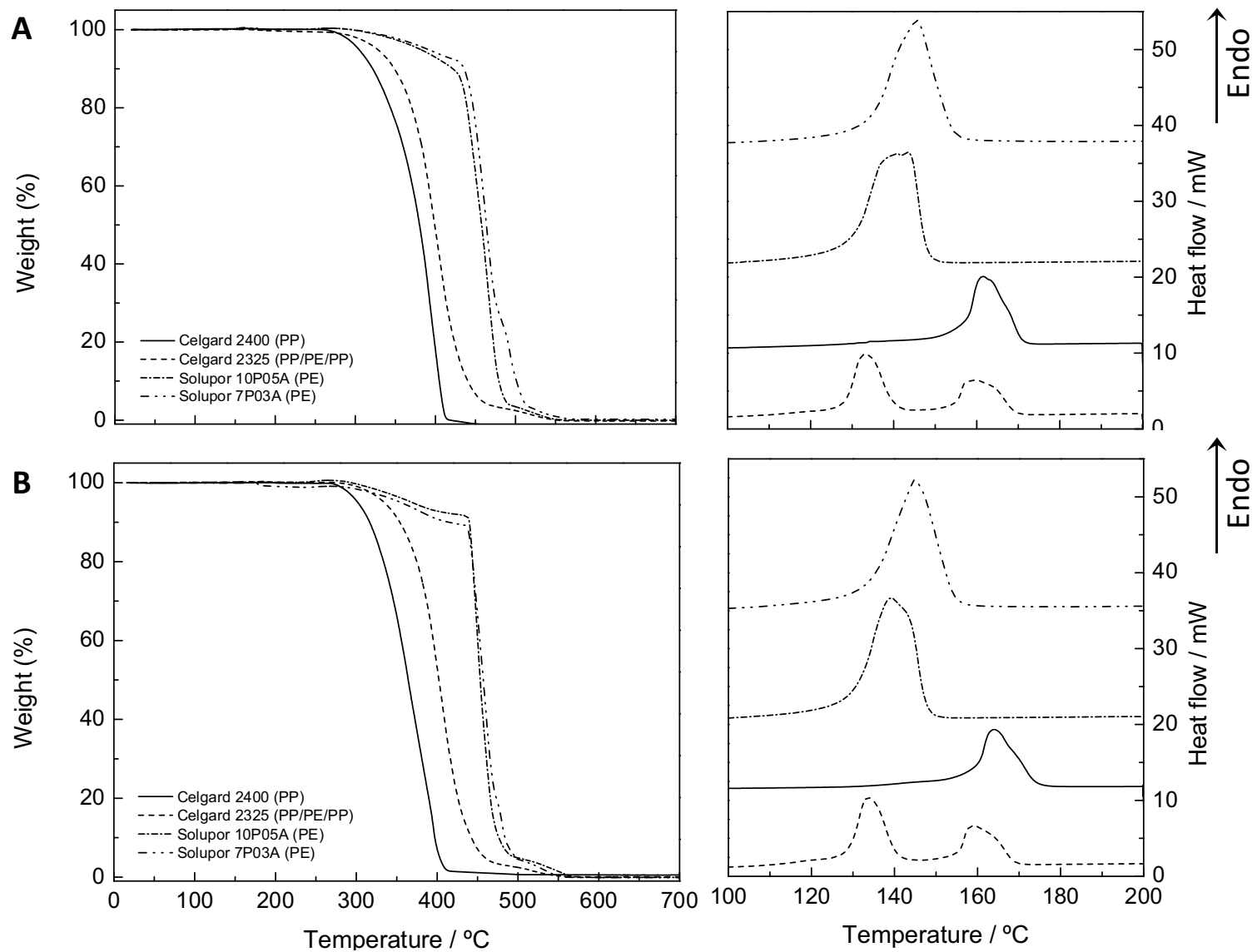

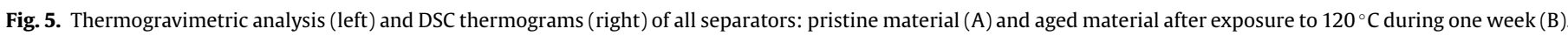

assumed that peroxide formation should not occur or should be minimized. If a significant oxidation would result from the thermal aging, the hydrophilicity of the pore surfaces should significantly increase. Now, the measured contact angles (see Section 3.1.4) does not reflect any substantial hydrophilicity. If stabilizers allow protecting efficiently polypropylene based separators from thermochemical degradations, they obviously do not prevent polymer chain degradations originating from depolymerization.

\subsubsection{Differential scanning calorimetry (DSC)}

A key property of separators, when used in Li-ion batteries, is their capability to shut it down before thermal runaway reactions occur, preventing further electrochemical activity in the cell. Shutdown usually takes place around the melting temperature of the polymer. Therefore, at the shutdown temperature, porosity significantly decreases until pores collapse, turning the macroporous structure into a non-porous insulating layer that (i) prevents any contact between the electrodes and (ii) is immiscible with the electrolyte, which results in a dramatic conductivity loss of the set separator/liquid electrolyte. In this work, the shutdown property was investigated using differential scanning calorimetry by determining melting temperature of the polymer, as shown in Fig. 5 (right). Melting temperature of Celgard ${ }^{\mathbb{R}} 2400$ (PP) separator was about $165^{\circ} \mathrm{C}\left(\Delta \mathrm{H}_{\mathrm{m}}=86 \mathrm{Jg}^{-1}\right)$, being effective for shutting down cells with relatively high thermal runaway temperature. On the other hand, PE separators (Solupor ${ }^{\circledR}$ ) showed lower shutdown temperature (about $140^{\circ} \mathrm{C} ; \Delta \mathrm{H}_{\mathrm{m}}=211 \mathrm{Jg}^{-1}$ ), preventing further electrochemical activity in cells earlier than those based on PP. For several applications, trilayered separators such as Celgard ${ }^{\mathbb{R}} 2325$ are preferred, since PE offers lower shutdown temperature and PP retains mechanical stability at and above the shutdown temperature. Regarding the aging effect, no significant differences regarding the area under melting peaks $\left(\Delta \mathrm{H}_{\mathrm{m}}\right)$ were observed between pristine and aged samples.

\subsubsection{Thermomechanical behavior}

The separator should be able to provide mechanical properties high enough not only to withstand the assembly process, but also to keep electrodes separated under typical operation conditions. Mechanical properties of all separators were characterized by quintuplicate in terms of tensile strength by applying $0.1 \mathrm{~N} / \mathrm{min}$ at a constant temperature, $30^{\circ} \mathrm{C}$. Stress-strain curves are presented in Fig. 6 for pristine material (continuous line) and aged material (dashed line). To investigate anisotropy produced by the dry fabrication process, Celgard ${ }^{\mathbb{R}}$ separators were tested both in machine and transverse direction (MD and TD). In case of Solupor ${ }^{\circledR}$ separators, although no anisotropy was evidenced, they were also investigated in two perpendicular directions, which are referred as 1 and 2 in graphs.

Regarding Celgard ${ }^{\circledR}$ separators, a remarkable difference in stress-strain curves was observed when measuring in machine (MD) or transverse (TD) direction. In TD, the behavior corresponds to a hard elastic polymer, where the horizontal plateau, taking place immediately after yielding, represents elongation at a constant stress. On the other hand, for measurements in MD, a softer yielding style was observed, since in this case, instead of a plateau corresponding to cold-drawing, strain hardening was observed before breaking. Moreover, significantly higher stress values were reached in MD ( $>125 \mathrm{MPa})$ when compared to TD $(<13 \mathrm{MPa})$, which is in agreement to previous results [24]. Such a remarkable variation in mechanical properties could be associated to morphology evolution during deformation as described by Chen 

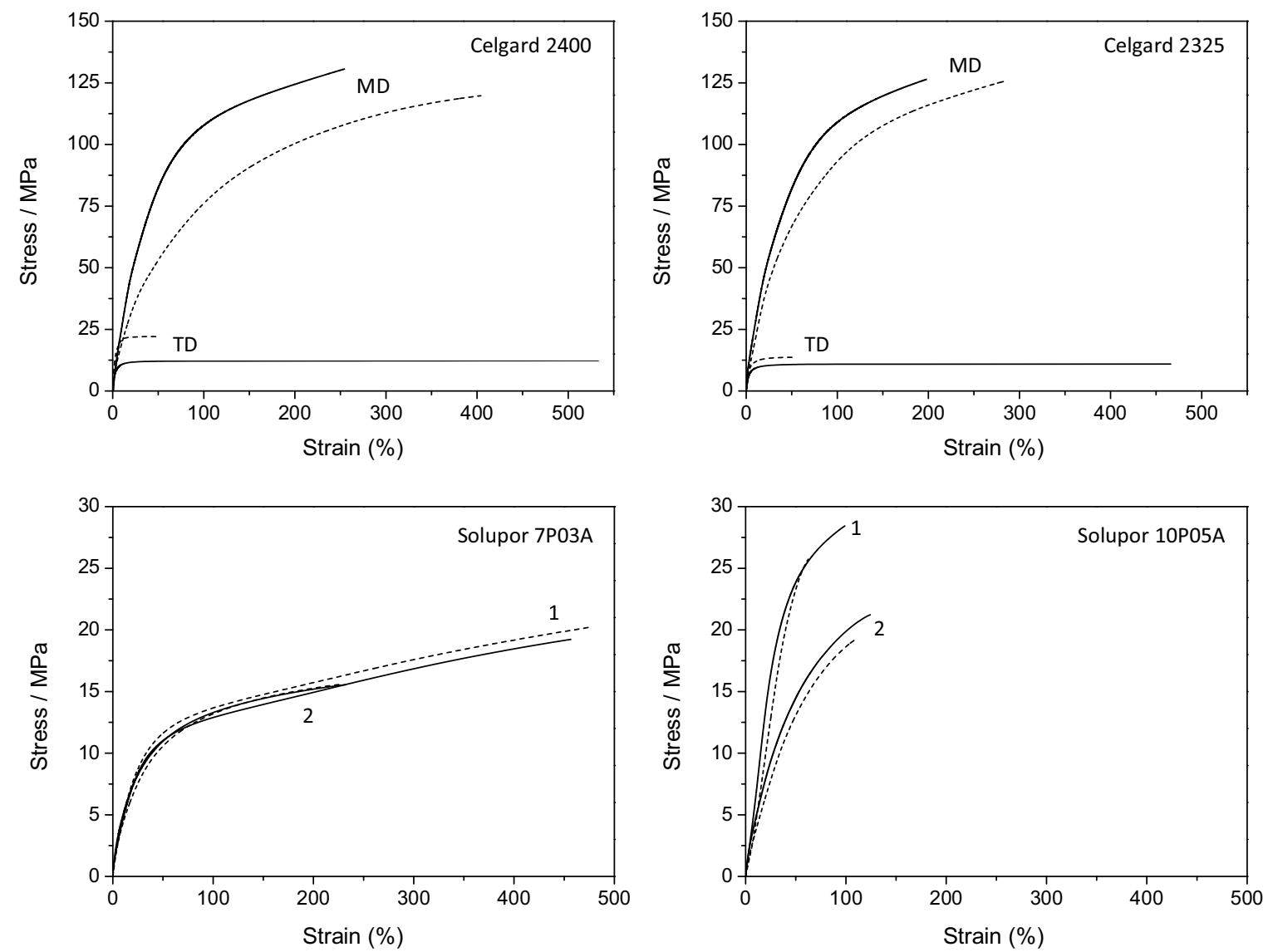

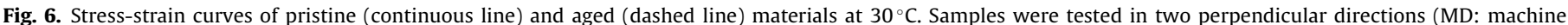
direction and TD: transverse direction for Celgard separators; 1 and 2 for Solupor separators).

et al. [36]. After annealing at $120^{\circ} \mathrm{C}$ during one week, a slight increase in tensile stress accompanied by a significant decrease in elongation at break was observed in probes tested in TD. This could be attributed to clogging and porous density reduction. Nevertheless, the opposite occurred in MD, where tensile stress slightly decreased and elongation at break increased. This is probably associated to the shrinkage of pores, which after the thermal treatment acquired a rounder shape, suggesting a reduced anisotropy and, therefore, a performance closer to that in TD.
In relation to stress-strain curves obtained for Solupor ${ }^{\circledR}$ separators, nearly isotropic mechanical properties were observed, since a similar behavior was obtained at both perpendicular directions investigated. At low strain values, deformation was elastic, followed by a nearly plastic behavior that lasted until previous to rupture, neither strain softening nor cold-drawing was observed. In this case, a slight decrease in mechanical properties was observed in aged samples, including tensile stress and strain. According to SEM measurements no significant differences in

Table 3

Mechanical properties of pristine and aged separators at $30^{\circ} \mathrm{C}(95 \%$ confidence; $n=5)$.

\begin{tabular}{|c|c|c|c|c|c|c|}
\hline Separator & Type & Direction & Tensile strength (MPa) & $\begin{array}{l}\mathrm{MD} / \mathrm{TD} \\
\mathrm{Or} \\
1 / 2\end{array}$ & Elongation at break (\%) & Young Modulus (MPa) \\
\hline 2400 & Pristine & $\begin{array}{l}\text { MD } \\
\text { TD }\end{array}$ & $\begin{array}{l}127 \pm 2 \\
11.7 \pm 0.2\end{array}$ & 10.9 & $\begin{array}{l}248 \pm 3 \\
530 \pm 3\end{array}$ & $\begin{array}{l}5.7 \pm 0.3 \\
4.0 \pm 0.1\end{array}$ \\
\hline 2400 & Aged & $\begin{array}{l}\text { MD } \\
\text { TD }\end{array}$ & $\begin{array}{l}119 \pm 2 \\
21.6 \pm 0.2\end{array}$ & 5.5 & $\begin{array}{l}381 \pm 14 \\
29 \pm 2\end{array}$ & $\begin{array}{l}3.8 \pm 0.4 \\
7.9 \pm 0.3\end{array}$ \\
\hline 2325 & Pristine & $\begin{array}{l}\text { MD } \\
\text { TD }\end{array}$ & $\begin{array}{l}122 \pm 1 \\
11.1 \pm 0.1\end{array}$ & 11.0 & $\begin{array}{l}198 \pm 2 \\
116 \pm 11\end{array}$ & $\begin{array}{l}6.2 \pm 0.5 \\
3.7 \pm 0.4\end{array}$ \\
\hline 2325 & Aged & $\begin{array}{l}\text { MD } \\
\text { TD }\end{array}$ & $\begin{array}{l}107 \pm 10 \\
13.4 \pm 0.1\end{array}$ & 8.0 & $\begin{array}{l}255 \pm 12 \\
74 \pm 7\end{array}$ & $\begin{array}{l}4.5 \pm 0.3 \\
4.8 \pm 0.1\end{array}$ \\
\hline 10P05A & Pristine & $\begin{array}{l}1 \\
2\end{array}$ & $\begin{array}{l}15.0 \pm 0.2 \\
18.9 \pm 0.1\end{array}$ & 0.8 & $\begin{array}{l}212 \pm 7 \\
417 \pm 11\end{array}$ & $\begin{array}{l}0.8 \pm 0.1 \\
0.9 \pm 0.1\end{array}$ \\
\hline 10P05A & Aged & $\begin{array}{l}1 \\
2\end{array}$ & $\begin{array}{l}19.9 \pm 0.2 \\
14 \pm 1\end{array}$ & 1.4 & $\begin{array}{l}443 \pm 14 \\
206 \pm 8\end{array}$ & $\begin{array}{l}1.0 \pm 0.1 \\
0.61 \pm 0.04\end{array}$ \\
\hline 7P03A & Pristine & $\begin{array}{l}1 \\
2\end{array}$ & $\begin{array}{l}20 \pm 1 \\
27 \pm 1\end{array}$ & 0.74 & $\begin{array}{l}112 \pm 8 \\
79 \pm 7\end{array}$ & $\begin{array}{l}0.9 \pm 0.1 \\
0.70 \pm 0.04\end{array}$ \\
\hline 7P03A & Aged & $\begin{array}{l}1 \\
2\end{array}$ & $\begin{array}{l}24.9 \pm 0.3 \\
18.6 \pm 0.3\end{array}$ & 1.34 & $\begin{array}{l}59 \pm 3 \\
102 \pm 2\end{array}$ & $\begin{array}{l}0.41 \pm 0.02 \\
0.49 \pm 0.04\end{array}$ \\
\hline
\end{tabular}

MD: machine direction; TD: transverse direction. 1: direction 1; 2: perpendicular direction. 
porosity were detected after thermal treatment, therefore, such a decrease could be associated to partial polymer degradation. Regarding elongation at break, it was lower for 7P03A in comparison to $10 \mathrm{P} 05 \mathrm{~A}$, which is in agreement with film thickness ( $50 \mu$ and $60 \mu$, respectively) and porosity (85\% and 83\%, respectively). Mechanical properties, including Young's modulus, elongation at break and tensile strength, were determined from stress-strain curves in Fig. 6 and are listed in Table 3. To highlight the anisotropy evolution upon thermal aging, the tensile strength ratios, MD/TD and $1 / 2$, were calculated for Celgard ${ }^{\circledR}$ and Solupor ${ }^{\circledR}$ separators respectively. MD/TD ratios, i.e. anisotropies, significantly decrease after the thermal aging process: the strong anisotropy generated by the Celgard $\AA$ separators elaboration vanishes partially with the samples heating. The much lesser anisotropy resulting of Solupor $\AA$ elaboration process seems less impacted by the thermal aging but, surprisingly, the tensile strength in direction 1 increases for both separators.

In general terms, Celgard ${ }^{\mathbb{R}}$ separators in MD presented higher mechanical performance when compared to Solupor ${ }^{\circledR}$ ones, including tensile strength and elongation at break. However, the anisotropic nature of Celgard ${ }^{\circledR}$ separators should be considered during the battery design, since when used in TD, ductility is considerably reduced, not the case for Solupor ${ }^{\circledR}$ separators, given their isotropic properties. This highlights the relevance of the morphology of the membrane not only during the battery assembly, but also during operation in order to assure a secure performance.

The effect of temperature on mechanical properties was also evaluated by heating samples from $30^{\circ} \mathrm{C}$ to $+200^{\circ} \mathrm{C}$, i.e. above $\mathrm{T}_{\mathrm{g}}$, at a heating rate of $5^{\circ} \mathrm{C} / \mathrm{min}$. Table 4 summarizes the maximum storage modulus obtained (E'). In Celgard ${ }^{\mathbb{R}}$ separators, a significant effect of temperature on the storage modulus was observed. Independently of the direction of measurement (MD or TD), E' values increased in aged samples of Celgard ${ }^{\circledR} 2400$ when compared to pristine ones. The anisotropy decreases and the E' in TD even exceeds the MD one. As XRD and DSC data do not allow drawing indisputable conclusions, the increased E' should be mainly ascribed to partial porosity clogging. Although anisotropy decreases too in Celgard ${ }^{\mathbb{R}} 2325$, the annealing effect appears more limited. Regarding Solupor ${ }^{\circledR}$ separators, given the isotropy provided by the network structure, not a clear trend was observed, since the slight differences in E' obtained under distinct conditions (temperature treatment and direction of measurement) moved through higher and lower values.

\subsection{Ionic conductivity of impregnated separators}

The separators were immersed in LP30 ${ }^{\circledR}$ during a controlled time; all the experiments being performed in a glove-box in argon atmosphere. According to r.t conductivities close to those of the State of the Art, an immersion time of one minute was found sufficient for both Solupor ${ }^{\circledR}$ separators. On the other hand, in case of Celgard ${ }^{\circledR}$ separators, the electrolyte uptake was much more laborious. After immersing them in $L P 30^{\circledR}$ for one hour, r.t conductivities of $3.7 \cdot 10^{-6}$ and $2.7 \cdot 10^{-4} \mathrm{~S} \mathrm{~cm}^{-1}$ were measured for pristine Celgard ${ }^{\circledR} 2325$ and Celgard ${ }^{\circledR} 2400$, respectively. Given such low conductivities, immersion time was increased from $1 \mathrm{~h}$ to $12 \mathrm{~h}$.

\subsubsection{Electrolyte set based on pristine separators}

From the Arrhenius plots at Fig. $6\left(-30^{\circ} \mathrm{C}\right.$ to $\left.+30^{\circ} \mathrm{C}\right)$, a higher thermal activation of conductivity can be noticed for electrolyte/ separator sets based on Solupor ${ }^{\circledR}$ separators. Moreover, a more or less sharp conductivity decrease is observed, roughly below $-10^{\circ} \mathrm{C}$, with conductivities ranging between $10^{-3} \mathrm{Scm}^{-1}$ at $30^{\circ} \mathrm{C}$ and $10^{-5} \mathrm{~S} \mathrm{~cm}^{-1}$ at $-30^{\circ} \mathrm{C}$. On the other hand, for electrolyte/separator sets based on Celgard ${ }^{\circledR}$ separators, conductivity plots did not exhibit the sharp drop observed at $-10^{\circ} \mathrm{C}$ for the Solupor ${ }^{\circledR}$ ones. Additionally, higher values were obtained, as expected, for the PP monolayer configuration, Celgard ${ }^{\circledR} 2400$, regarding the $\mathrm{PP} / \mathrm{PE} / \mathrm{PP}$ trilayered one, i.e. Celgard $^{\circledR} 2325$, whose set exhibited the lowest conductivity of the whole of the sets. Despite the highest conductivity obtained for Celgard ${ }^{\mathbb{R}} 2400$ based electrolyte is comparable to values obtained for both Solupor ${ }^{\circledR}$, it should be noticed that this latter was obtained after a 1 minute immersion time in LP30 ${ }^{\circledR}$, while in case of Celgard ${ }^{\circledR} 2400,12$ hours were necessary in order to obtain such a conductivity range.

The McMullin number $\left(\mathrm{N}_{\mathrm{M}}\right)$ and tortuosity $\tau$ were estimated to characterize the effect of the macroporous separator on the ionic conductivity of the liquid electrolyte (LP30 $®$ ) according to Eqs. (1) and (2) [24]:

$\mathrm{N}_{\mathrm{M}}=\sigma_{0} / \sigma_{\text {eff }}$

$\tau=\left(\mathrm{N}_{\mathrm{M}} \mathrm{X} \varepsilon\right)^{1 / 2}$

where $\sigma_{0}$ is the conductivity of the liquid electrolyte $\left(\mathrm{LP} 30^{\circledR}\right), \sigma_{\text {eff }}$ the conductivity of the set separator + liquid electrolyte and $\varepsilon$ is the porosity ratio.

Table 5 gathers all data $\left(\sigma_{\text {eff }}, N_{M}, \tau\right)$ of the sets 'liquid electrolyte + pristine separators'. The $\mathrm{N}_{\mathrm{M}}$ values, calculated at $21^{\circ} \mathrm{C}$, ranged between 4.8 (Solupor ${ }^{\circledR} 7 \mathrm{P03A}$ ) and 17.9 (Celgard ${ }^{\circledR} 2325$ ). The latter cumulates, therefore, two technological

Table 5

Effective conductivity ( $\left.\sigma_{\text {eff }}\right)$, MacMullin number $\left(\mathrm{N}_{\mathrm{M}}\right)$ and tortuosity $(\tau)$ of the set "LP30 ${ }^{\mathbb{R}}+$ separators" at $21^{\circ} \mathrm{C}$.

\begin{tabular}{lllll}
\hline Separator & $\sigma_{\text {eff }}\left(\mathrm{mS} \mathrm{cm}^{-1}\right)$ & $\mathrm{N}_{\mathrm{M}}$ & $\varepsilon \%^{\mathrm{a}}$ & $\tau$ \\
\hline Celgard $^{\mathbb{R}} 2400$ & 1.7 & 7.7 & 45.4 & 1.7 \\
Celgard $^{\mathbb{R}} 2400$ (Aged) & 0.1 & 128 & 41.6 & 6.5 \\
Celgard $^{\mathbb{R}} 2325$ & 0.72 & 18 & 44.1 & 2.6 \\
Celgard $^{\mathbb{R}} 2325$ (Aged) & 0.24 & 53 & 57.4 & 5.0 \\
Solupor $^{\mathbb{R}}$ 10P05A & 1.7 & 7.7 & 75.9 & 2.7 \\
Solupor $^{\mathbb{1}}$ 10P05A (Aged) & 1.3 & 9.7 & 66.9 & 2.1 \\
Solupor $^{\mathbb{R}}$ 7P03A & 2.7 & 4.8 & 78.6 & 1.8 \\
Solupor $^{\mathbb{R}}$ 7P03A (Aged) & 3.3 & 3.8 & 69.2 & 1.6 \\
\hline
\end{tabular}

$\sigma_{0}=9.8 \cdot 10^{-3} \mathrm{~S} \mathrm{~cm}^{-1} ; \mathrm{T}=21^{\circ} \mathrm{C}$.

a Data obtained from $\mathrm{Hg}$ porosimetry.

Table 4

Storage Modulus (E') for all investigated separators at $30^{\circ} \mathrm{C}$.

\begin{tabular}{|c|c|c|c|c|}
\hline & \multicolumn{4}{|l|}{$\mathrm{E}^{\prime}(\mathrm{MPa})$} \\
\hline & \multicolumn{2}{|c|}{ 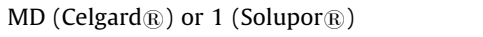 } & \multicolumn{2}{|c|}{ 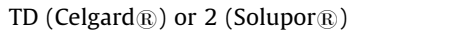 } \\
\hline & Pristine & Aged & Pristine & Aged \\
\hline Celgard ${ }^{\mathbb{R}} 2400$ & 748 & 806 & 466 & 1046 \\
\hline Celgard ${ }^{\mathbb{R}} 2325$ & 1330 & 1197 & 568 & 737 \\
\hline Solupor ${ }^{\sqrt{R}} 10 \mathrm{P} 05 \mathrm{~A}$ & 283 & 353 & 357 & 232 \\
\hline Solupor ${ }^{\mathbb{1}} 7 \mathrm{P03A}$ & 278 & 210 & 510 & 190 \\
\hline
\end{tabular}

MD: machine direction; TD: transverse direction. 1: direction 1, 2: perpendicular to 1. 

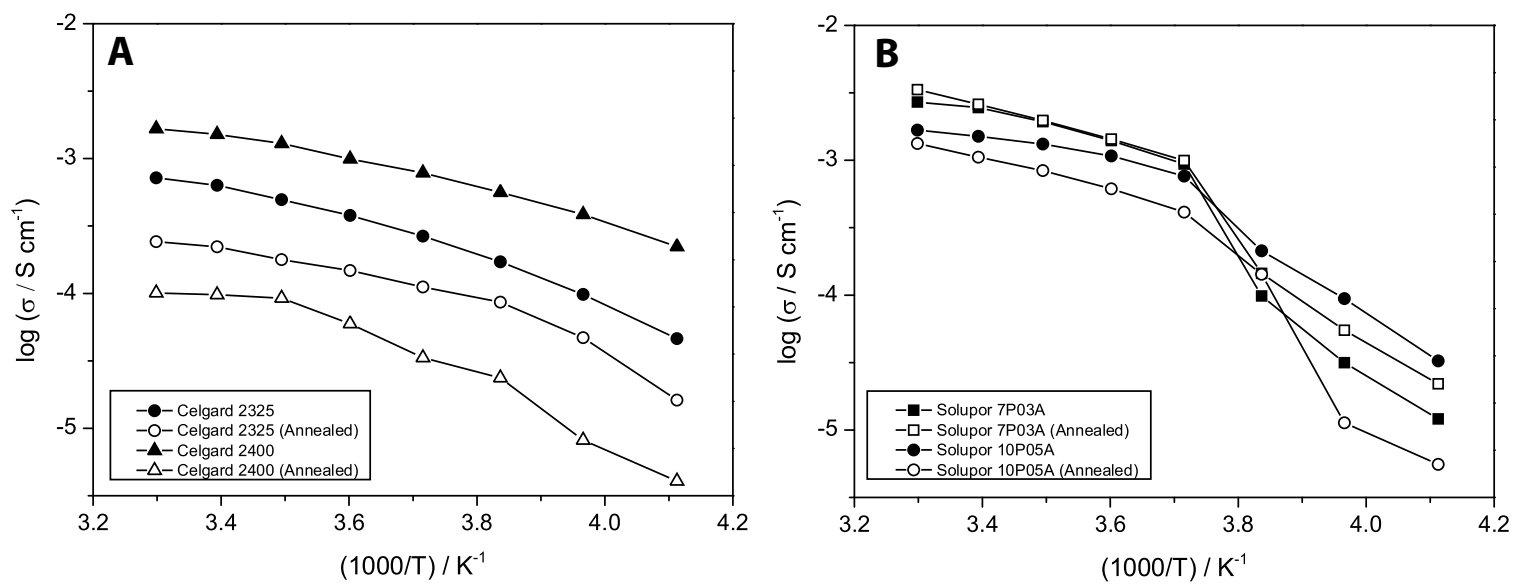

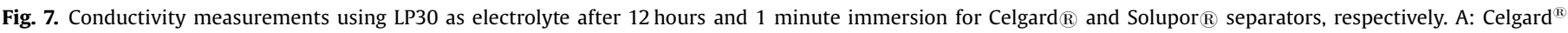
separators (PP and PP/PE/PP); B: Solupor ${ }^{\mathbb{R}}$ separators (PE).

drawbacks i.e. a long immersion time and a high $\mathrm{N}_{\mathrm{M}}$, even though partly counterbalanced by an increased safety.

\subsubsection{Electrolyte set based on thermally aged separators}

As seen in Fig. 7 and Table $5\left(\sigma_{\text {eff, }} \mathrm{N}_{\mathrm{M}}\right.$ and $\left.\tau\right)$, electrolytes based on pristine and aged Solupor ${ }^{\circledR} 7 \mathrm{P03A}$ exhibited close conductivities, aging leading even to slightly higher conductivities below $-10{ }^{\circ} \mathrm{C}$. A higher gap that, nonetheless, did not exceed a factor of two was observed for Solupor ${ }^{\mathbb{R}} 10 \mathrm{P} 05 \mathrm{~A}$; the aged separator being less performing in the whole temperature range. On the other hand, regarding both Celgard ${ }^{\circledR}$ separators, their aging induced a neat conductivity drop. This is illustrated by $\mathrm{N}_{\mathrm{M}}$ exceeding 50 and 120 for Celgard ${ }^{\circledR} 2325$ and Celgard ${ }^{\circledR} 2400$, respectively. Surprisingly, the aging effect was much more significant on the Celgard $^{\mathbb{R}} 2400$ than on the Celgard ${ }^{\mathbb{R}} 2325$, the conductivity gap approaching two orders of magnitude at $-30^{\circ} \mathrm{C}$. These data are however in agreement with the porosimetry ones.

From the whole of these data, it appears that pristine polypropylene based separators led to the highest $N_{M}$ values, related to higher porous volume and pore diameter of pristine Solupor ${ }^{\circledR}$. These morphological and structural differences favor the conductivities of Solupor $\AA$ based electrolytes as well as the swelling kinetic. Thermal aging resulted in dramatic conductivity losses for Celgard ${ }^{\circledR}$ based electrolytes, contrary to the slight variations observed on aged Solupor ${ }^{\circledR}$ based electrolytes.

\section{Conclusions}

Different commercially available macroporous separators were investigated to assess the effect of high exposure time at high temperatures. According to DSC and DMA, trilayered separators ( $\mathrm{PP} / \mathrm{PE} / \mathrm{PP}$ ) appear to be the most efficient alternative to prevent thermal runaway, since PE provides a lower shutdown temperature, while PP improves mechanical stability at and above melting temperature. Nevertheless, in terms of conductivity, Solupor ${ }^{\circledR}$ separators demonstrated to be superior, given their fibrous network and larger pore size, improved electrolyte retention is achieved. Although all separators presented degraded performance when submitted to an aging treatment, more significant effects were observed on Celgard ${ }^{\mathbb{R}}$ separators, i.e. conductivity and tensile strength. From the four tested separators Solupor ${ }^{\circledR} 7 \mathrm{P} 03 \mathrm{~A}$ seems to be the most appropriate to the required thermal operation range. Thermal aging was performed ex-situ as $L P 30^{\circledR}$ cannot be used at temperatures exceeding $50-60^{\circ} \mathrm{C}$. As, the polar aprotic electrolytes have very poor affinity towards usual porous hydrophobic polyolefin, a swelling at high temperature of the polymeric interphase has not to be feared. We think therefore that the ex-situ thermal aging is representative of the evolution, in presence of liquid electrolyte, of these separators. But performances of set separator/liquid electrolyte are still 'Terra Incognita'. Further work is currently undergoing towards the evaluation of these separators with selected liquid electrolytes able to sustain higher temperatures.

\section{Acknowledgements}

This work has been supported by Projects funded by the regional government (Comunidad de Madrid through MATERYENER3CM S2013/MIT-2753) and the Spanish Government, MICINN (MAT2013-46452-C4-3R).

$\mathrm{J}-\mathrm{Y}$ Sanchez acknowledges the CONEX Programme, funding received from Universidad Carlos III de Madrid, the European Union's Seventh Framework Programme for research, technological development and demonstration (Grant agreement $n^{\circ}$ 600371), Spanish Ministry of Economy and Competitiveness (COFUND201340258) and Banco Santander.

\section{References}

[1] M. Gauthier, A. Bélanger, P. Bouchard, B. Kapfer, S. Ricard, G. Vassort, M. Armand, J.-Y. Sanchez, L. Krause, Large lithium polymer battery development The immobile solvent concept, J. Power Sources 54 (1995) 163.

[2] S. Matsui, T. Muranaga, H. Higobashi, S. Inoui, T. Sakai, Liquid-free rechargeable Li polymer battery, J. Power Sources 97-98 (2001) 772.

[3] M. Watanabe, T. Hirakimoto, S. Mutoh, A. Nishimoto, Polymer electrolytes derived from dendritic polyether macromonomers, Solid State Ionics 148 (2002) 399.

[4] A. Nishimoto, M. Watanabe, Y. Ikeda, S. Kohjiya, High ionic conductivities of new polymer electrolytes based on high molecular weight polyether comb polymers, Electrochimica Acta 3 (1998) 1177.

[5] F. Alloin, D. Benrabah, J.-Y. Sanchez, Comparative ion transport in several polymer electrolytes, J. Power Sources 68 (2) (1997) 372

[6] F. Alloin, J.-Y. Sanchez, M. Armand, Triblock copolymers and networks incorporating oligo(oxyethylene) chains, Solid State Ionics 60 (1-3) (1993) 3.

[7] F. Alloin, J.-Y. Sanchez, New solvating polyether networks, Electrochimica Acta $40(13-14)(1995) 2269$.

[8] G. Feuillade, P. Perche, Ion-conductive macromolecular gels and membranes for solid lithium cells, J. Appl. Electrochem. 5 (1) (1975) 63.

[9] A.M. Stephan, Review on gel polymer electrolytes for lithium batteries, European Polymer Journal 42 (2006) 21.

[10] F. Croce, F. Gerace, G. Dautzemberg, S. Passerini, G.B. Appetechi, B. Scrosati, Synthesis and characterization of highly conducting gel electrolytes, Electrochimica Acta 39 (14) (1994) 2187.

[11] J. Saunier, N. Chaix, F. Alloin, J.P. Belieres, J.-Y. Sanchez, Electrochemical study of polymethacrylonitrile electrolytes - Conductivity study of polymer/salt complexes and plasticized polymer electrolytes. Part I, Electrochimica Acta 47 (8) (2002) 1321. 
[12] H.-S. Min, J.-M. Ko, D.-W. Kim, Preparation and characterization of porous polyacrylonitrile membranes for lithium-ion polymer batteries, J. Power Sources 119-121 (2003) 469.

[13] J.M. Tarascon, A.S. Goztz, C. Schmutz, F. Shokoohi, P.C. Warren, Performance of Bellcore's plastic rechargeable Li-ion batteries, Solid State Ionics 86-88 (1996) 46.

[14] J. Saunier, F. Alloin, J.-Y. Sanchez, B. Barrière, Plasticized microporous PVDF separators for lithium-ion batteries. Part I: Swelling behaviour of dense membranes with respect to the liquid electrolyte. Characterization of the swelling equilibrium, J. Polym. Sci. Pt. B-Polym. Phys. 42 (2004) 532.

[15] C.S.Martinez-Cisneros,B.Levenfeld,A.Varez,J.-Y.Sanchez,Developmentof sodium-conductingpolymerelectrolytes:comparisonbetweenfilm-casting and filmsobtainedviagreenprocesses,ElectrochimicaActa192(2016)456.

[16] P. Arora, Z. Zhang, Battery separators, Chem. Rev. 104 (2004) 4419

[17] J.Saunier,F.Alloin,J.-Y.Sanchez,L.Maniguet,PlasticizedmicroporousPVDF separatorsforlithium-ionbatteriesPartIII:StudyofthedensePVdF membranes swellingbehaviourintheliquidelectrolyte.Gelpropertiesand PVdFmembrane irreversiblemodificationsunderswellingintheliquid electrolyte,J.Polym.Sci.Pt. B-Polym.Phys.42(2004)2308.

[18] A.Magistris,P.Mustarelli,E.Quartarone,P.Piaggio,A.Bottino,Poly (vinylidenefluoride)-basedporouspolymerelectrolytes,Electrochim.Acta 46 (2001)1635.

[19] D. Langevin, OT Nguyen, S. Marais, S, Karademir, J-Y Sanchez, C. Iojoiu, M. Martinez, P. Judeinstein, C. Chappey, High-Temperature Ionic-Conducting Material: Advanced Structure and Improved Performance, J. Phys. Chem. C 117 (30) (2013) 15552

[20] F. Boudin, X. Andrieu, C. Jehoulet, I.I. Olsen, Microporous PVdF gel for lithiumion batteries, J. Power Sources 81 (1999) 804.

[21] T.Michot,A.Nishimoto,M.Watanabe,ElectrochemicalPropertiesofpolymer gel electrolytesbasedonpoly(vinilidenefluoride)copolymerand homopolymer ElectrochimicaActa45(2000)1347.

[22] J.Saunier,F.Alloin,J.-Y.Sanchez,G.Caillon,Thinandflexiblelithium-ion batteries: investigationofpolymerelectrolytes,J.PowerSources 119-121 (2003) 454.

[23] C.Arbizzani,F.Colo,F.DeGiorgio,M.Guidotti,M.Mastragostino,F.Alloin,M. Bolloli, Y.Molmeret,J.-Y.Sanchez,Anon-conventionalfluorinatedseparatorin highvoltagegraphite/LiNi0.4Mn1.604cells,J.PowerSources246(2014)299.
[24] D. Djian, F. Alloin, S. Martinet, H. Ligner, J.-Y. Sanchez, J. Power Sources 172 (2007) 416

[25] J.M.AmarillaAlvarez,B.LevenfeldLaredo,M.E.SotomayorLozano,A.Várez Alvarez,J-Y.Sanchez,W.BucheliErazo,Electrodosparabateríasrecargablesde Litio.DemandNoP201630313,Spain,March2016.UniversidadCarlosIIIde Madrid,ConsejoSuperiordeInvestigacionesCientíficas.

[26] S.S. Zhang, A review on the separators of liquid electrolyte Li-ion batteries, J. Power Sources 164 (2007) 351.

[27] Y.L. Joo, O.H. Han, H.K. Lee, J.K. Song, Characterization of ultra high molecular weight polyethyelene nascent reactor powders by X-ray diffraction and solid state NMR, Polymer 41 (2000) 1355.

[28] K. Cho, D.N. Saheb, J. Choi, H. Yang, Real time in situ X-ray diffraction studies on the melting memory effect in the crystallization of beta-isotactic polypropylene, Polymer 43 (4) (2002) 1407.

[29] J.L. Gineste, G. Pourcelly, Polypropylene separator grafted with hydrophilic monomers for lithium batteries, J. Membr. Sci. 107 (1995) 155

[30] K.J.Kim,J.-H.Kim,M.-S.Park,H.K.Kwon,H.Kimb,Y.-J.Kim,Enhancementof electrochemicaland thermalpropertiesofpolyethyleneseparatorscoated with polyvinylidenefluoride-hexafluoropropyleneco-polymerforLi-ion batteries,J. PowerSources198(2012)298.

[31] S. Menne, J. Pires, M. Anouti, A. Balducci, Protic ionic liquids as electrolytes for lithium-ion batteries, Electrochemistry Communication 31 (2013) 39-41.

[32] R.F.SchwenkerJr.,R.K.Zuccarello,Differentialthermalanalysisofsynthetic fibers, J.PolymerSciencePartC:PolymerSymposia6(1)(1964)1-16.

[33] K. Kishore, P.V.R. Verneker, Correlation between heats of depolymerization and activation energies in the degradation of polymers, Polymer letters edition 14 (1976) 761.

[34] L. Contat-Rodrigo, A. Ribes-Greus, C.T. Imrie, Thermal analysis of high-density polyethylene and low-density polyethylene with enhanced biodegradability, J. Appl. Polym. Sci. 86 (2002) 764.

[35] S. Sarrabi, X. Colin, A. Tharkhtchi, Dégradation thermique du polypropylene au cours du rotomoulage, Matériaux \& Techniques (2009) 1-14, doi:http://dx.doi. org/10.1051/mattech:2009001 EDP Sciences.

[36] J. Chen, Y. Yan, T. Sun, Y. Qi, X. Li, Deformation and fracture behaviors of microporous polymer separators for lithium ion batteries, RSC Adv. 4 (2014) 14904. 